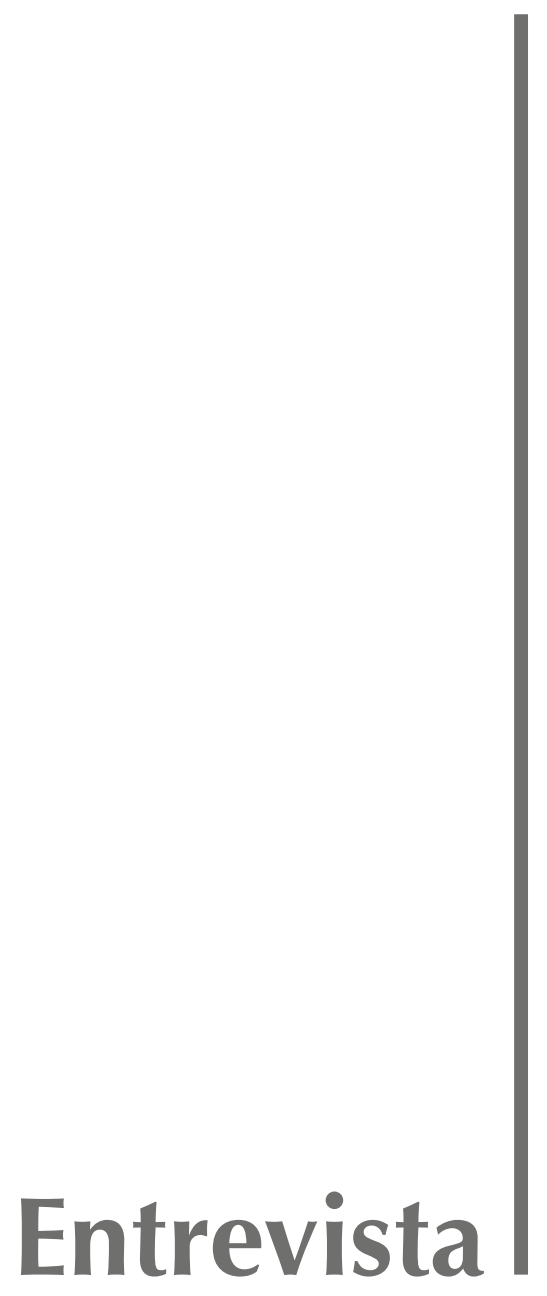





\title{
Entrevista a Steve J. Stern: "El concepto mismo de memoria tiene una historia que nace a través de una lucha"
}

Este artículo se encuentra disponible para su descarga gratuita en www.anuariocdh.uchile.cl

Por Marianne González y Marcela Sandoval

\begin{abstract}
Marianne González Le Saux es abogada, Licenciada en Ciencias Jurídicas y Sociales de la Universidad de Chile. Actualmente es investigadora del Programa Democracia y Derechos Humanos del Centro de Derechos Humanos, Facultad de Derecho, Universidad de Chile.
\end{abstract}

\begin{abstract}
Marcela Sandoval Osorio es periodista, Licenciada en Comunicación Social y Magister Artium en Literatura por la Universidad de Santiago de Chile. Fue investigadora del Centro de Derechos Humanos de la Universidad de Chile. Actualmente, es la coordinadora del proyecto "Agendas regionales de derechos humanos en Chile" del Instituto Nacional de Derechos Humanos.
\end{abstract}

\section{Introducción}

Steve J. Stern es académico de la Universidad de Wisconsin-Madison y es uno de los historiadores norteamericanos más versátiles e influyentes en el ámbito de la historiografía latinoamericana. Ha destacado por sus trabajos sobre historia indígena andina, estudios coloniales, el fenómeno de Sendero Luminoso en el Perú, y actualmente por su titánica obra, la Trilogía La caja de la memoria del Chile de Pinochet. Su primer tomo, Recordando el Chile de Pinochet en vísperas de Londres 1998, fue publicado en 2009 en español ${ }^{1}$. El segundo y el tercer tomo se encuentran actualmente en proceso de traducción ${ }^{2}$. En esta obra, Stern analiza con gran rigurosidad intelectual y sobre todo con una excepcional sutileza y sensibilidad, cómo la dictadura y la posterior transición democrática en Chile se encuentran a la base de las disputas por la memoria entre distintos actores sociales. Combinando distintos registros y perspectivas de análisis, el autor recorre no solamente el desenvolvimiento de los hechos de la represión dictatorial en Chile y el ulterior proceso de lucha por la transición hacia la democracia, sino que permite aprehender el significado profundo de estos hechos en la conciencia colectiva, lo que Stern Ilama la "lucha por las mentes y corazones" de Chile, en los distintos relatos que marcan las memorias de la época, y que cobran una importancia estratégica tanto "política, moral y existencialmente" en las discusiones actuales sobre derechos humanos, movimientos sociales y profundización democrática.

Como un observador externo, pero que a la vez se encuentra íntimamente comprometido con esta historia, Steve Stern tiene una mirada que permite poner en perspectiva histórica muchos fenómenos que han removido a la sociedad chilena en este último año, así como situarlos en el contexto latinoamericano. Así, Steve Stern nos regaló varias horas de su tiempo y con enorme claridad, simpatía y calidez nos permitió conocer su mirada sobre la vinculación entre memoria y derechos humanos, así como una evaluación de las políticas de los Estados de la región -Chile

1 STERN, Steve J. Recordando el Chile de Pinochet en vísperas de Londres 1998. Santiago: Ediciones Universidad Diego Portales, 2009.

2 STERN, Steve J. Battling for Hearts and Minds: Memory Struggles in Pinochet's Chile, 1973-1988. Durham \& London: Duke University Press, 2006; STERN, Steve J. Reckoning with Pinochet: The Memory Question in Democratic Chile, 1989-2006. Durham \& London: Duke University Press, 2010. 
en particular- en materia de reparación, investigación y sanción de las violaciones de derechos humanos cometidas en el pasado. Asimismo, pudimos explorar su interpretación de los movimientos sociales que han removido a Chile -pero también a otras partes del mundo- durante el 2011, y de la resignificación que en ese contexto se produce respecto de las luchas por la memoria tanto por las nuevas generaciones como por los pueblos indígenas. Por último, discutimos los desafíos de la educación en derechos humanos, así como de los dilemas éticos y políticos a los que se ve enfrentada la academia en temas de memoria y derechos humanos.

\section{ENTREVISTA}

\section{Marianne González: ¿A qué nos referimos cuando hablamos de "memoria", cómo podemos concebirla? ¿Y cómo se vincula con la idea de derechos humanos?}

Steve Stern: Mi visión de la memoria es a través de la historia, es decir, estudiando en qué momento nació el concepto de una manera que tenía cierta resonancia cultural y política. Por ejemplo, poco tiempo después de instalada en Chile la Junta Militar y la dictadura de Pinochet, en la época del Comité Pro Paz y los inicios de la Vicaría de la Solidaridad, la memoria como palabra todavía no tenía eco. Y tampoco los derechos humanos. Los actores venían de otra época, en que el tema era la revolución, la reforma social, la reforma agraria, pero no los derechos humanos, y menos la memoria. Desde la izquierda, el tema de derechos humanos se veía como algo burgués, que se había utilizado en contra de enfrentar la necesidad de grandes transformaciones socioeconómicas. Entonces, cuando comienza la represión después del golpe de Estado, la idea de derechos humanos fue todo un descubrimiento. En un principio, las personas estaban respondiendo a una emergencia, a la necesidad de solidaridad. Pero poco a poco iban entendiendo la seriedad y la profundidad de lo que podía ser una concepción de derechos humanos.

Con el paso del tiempo, ya a fines de los años 70, está muy instalado el lenguaje de derechos humanos. En 1978 se organizó en Santiago el año de los derechos humanos. Y Carter está en Estados Unidos. Así que, además de lo que está pasando en Chile -y en Argentina- también hay un eco que tiene una resonancia distinta en el Norte.

Sin embargo, todavía la memoria como tal no tenía un eco sagrado en la cultura. Se puede documentar, y es lo que hice en el Tomo II de la Trilogía, que lo que ocurre es que la idea de memoria nace porque se genera una pugna entre las distintas formas de leer el pasado más reciente y la realidad del país. Se puso en pelea por un lado una "memoria salvadora" - que es una memoria de la Junta Militar y de las personas que la apoyaron-, que teóricamente, salvó al país del desastre. Y por otro lado se empezaron a plantear memorias alternativas, disidentes. La "memoria como una herida abierta", como una ruptura que destruye vidas y familias, en la que obviamente la Agrupación de Familiares de Detenidos-Desaparecidos era importante, y también una idea de la "memoria como la persecución y el despertar" a lo que está pasando en el país, que nació del intento por documentar la persecución multifacética del Régimen, y que genera un nacer de conciencia en muchas personas. Los problemas económicos existentes durante la dictadura, pero especialmente las persecuciones, los exilios, la prisión y en algún momento la tortura, comienzan a hacerse realidad para muchos.

Entonces, para asfixiar estas memorias disidentes, el Régimen, a nivel cultural, liga la idea de un olvido consciente con una adaptación legal, que es promulgar su Decreto Ley de Amnistía. Con esto, se busca instalar la idea que todos estos problemas eran del pasado, y que quedarse en los rencores no va a ayudar al país a avanzar. La guerra mítica que justificó la memoria salvadora se acabó, y lo que se necesita hacer es institucionalizar. Esta es la idea de la "memoria como una caja cerrada", como un olvido consciente. 
En ese momento entonces, se comienza a desarrollar un lenguaje sobre la memoria y el olvido como un discurso contestatario. Y es ahí, a finales de los años 70, y especialmente a principio de los años 80 que la idea de memoria -es decir, no olvidarnos de quienes están todavía perseguidos- empieza a tener resonancia, y se empieza a definir el problema de derechos humanos en asociación con una lucha de memoria contra el olvido. Entonces, cuando llega el momento de las protestas en los años 80, y después con el Plebiscito, ya está muy establecido un lenguaje en que la memoria tiene valor o eco cultural. Y esto quiere decir que para los países del Cono Sur, toda la legitimidad de un régimen militar o una dictadura, y de las luchas en contra de estos regímenes, están íntimamente asociadas al problema de la memoria. Cuando se llega a la transición democrática, cuando de alguna manera hay que enfrentar qué pasó y qué vamos a hacer con esta herencia, ya el tema de la memoria está muy instalado y tiene resonancia. Así que el concepto mismo de memoria tiene una historia que nace a través de una lucha.

Marianne González: En Latinoamérica parece haber un contexto general que permite que esta idea de memoria junto con los derechos humanos nazca en Chile, pero también en Argentina, en Uruguay, etc. Esta asociación tiene eco en nuestro país, pero también se forja en otros lugares al mismo tiempo. Algo similar parecería ocurrir en Europa después de la Segunda Guerra Mundial, pues la idea de recordar lo que pasó con el Genocidio se instala al mismo tiempo que se universaliza la idea de derechos humanos, con la Declaración Universal de 1948. ¿Cómo se conecta la vinculación entre memoria y derechos humanos con este contexto más global?

Steve Stern: Voy a dividir esta pregunta en dos partes. Primero, vamos a hablar sobre las redes Sur a Sur. Al respecto, es un error ver la historia global como una doctrina que se crea en el Norte, y que lo que existe en el Sur, son las particularidades. Pensándolo así, ¿qué es lo que vemos en América Latina? Ocurren tres fenómenos.

Primero, los grupos empiezan a conectarse a través de distintos países. Un grupo que era muy estratégico en estas luchas, y muy emblemático a nivel simbólico en Chile era la Agrupación de Familiares de Detenidos-Desaparecidos. Hay otras agrupaciones semejantes en otros países, y empiezan, en 1980 o 1981, a reunirse internacionalmente de una manera un poco más sistemática. Y empiezan a desarrollar lenguajes en común, comparar experiencias, hablar sobre el problema en América del Sur en general. De esta forma, hay redes de solidaridad o de encuentro Sur a Sur. Y no solo en el tema de derechos humanos: por ejemplo, se puede pensar en los encuentros feministas que se dieron en América Latina también en esa época.

Un segundo nivel es la importancia simbólica de Chile a nivel mundial. Creo que Chile tiene un impacto muy importante a nivel de la cultura global -no solo Chile, por supuesto, porque Argentina también-, pero Chile tiene un impacto muy especial por dos motivos. Primero, el golpe en 1973 Ilamó la atención a muchos, y provocó mucha denuncia y rabia en distintas partes del mundo que, en otros contextos, eran partes divididas. Es decir, en la Unión Soviética y los países alineados con ellos, lo que pasó en Chile fue horrible, había que denunciar. En Escandinavia, había que denunciar. También en los países de Europa del Oeste, que en esa época tenían gobiernos de centroizquierda. Chile era un lugar simbólico muy fuerte. Allende mismo lo sabía, cuando fue con su famoso discurso a las Naciones Unidas en diciembre de 1972, diciendo "vengo de un país pequeño, donde se respeta... etc.". Allende entendía el simbolismo de ese país para muchos, en distintas parte en que las fronteras estándares establecidas por la Guerra Fría ya no funcionaban del todo. Y además, al principio la Junta Militar no había aprendido a sofocar la denuncia. Las imágenes del bombardeo de La Moneda estaban en todas partes: a nivel simbólico, Chile fue muy potente.

Y en un tercer nivel, está el tema del exilio. 
Marcela Sandoval: Considerando además la particularidad del exilio chileno, que era un grupo de intelectuales muy importante que seguía produciendo fuera del país...

Steve Stern: Exacto. Creo que había mucha heterogeneidad entre los exiliados chilenos. Algunos no se metieron en activismo, pero otros sí. Y tenían un impacto en las redes y en las conciencias que iban naciendo en el Norte y en otros países latinoamericanos, como en México, etc. De cierta manera, sin ser presos del espejo que estamos rechazando, no voy a decir que el Sur era el único factor relevante en expandir la universalidad de los derechos humanos, pero era muy potente en expandir esta conciencia, y en hacer que esa doctrina tuviera relevancia para el Sur.

Si pensamos ahora en la segunda parte de tu pregunta, en 1948, ¿qué es lo que pasa? Nace una cierta conciencia al momento de la Declaración Universal de Derechos Humanos, pero nace en un momento en que gran parte del mundo se encuentra colonizado todavía, y en el que está gestándose a la vez la Guerra Fría. Esto hace que la promesa de la universalidad no se cumpla tanto como debería. Es decir, son derechos universales, pero especialmente relevantes para personas "civilizadas", para países "civilizados". Creo que ese supuesto empieza a destruirse no solo por Chile y América Latina: también por Vietnam y otros lugares. Pero se comienza a desmoronar. Y el efecto de lo que pasó en Chile y también, hasta cierto punto, en Argentina, fue fundamental en el desmoronamiento de ese supuesto que establecía una jerarquía entre países.

Marcela Sandoval: Otro tema que nos interesa discutir es la forma de valorar los esfuerzos que se han hecho desde el Estado, cómo se ha avanzado en iniciativas de memoria, justicia y reparación, pues existe una visión un poco crítica respecto a qué tan sustantivos han sido estos avances. Un punto más allá en esta discusión es la creación de institucionalidad de derechos humanos. Hoy contamos en Chile con el Museo de la Memoria y también con el Instituto Nacional de Derechos Humanos. A la luz de la experiencia comparada ¿cómo ves los avances de Chile en esta materia? Porque, si uno evalúa nuestra transición respecto de las democracias en Argentina o en Uruguay, podría incluso decirse que nuestros esfuerzos han sido en algunos sentidos más bien lentos o más bien cautos.

Steve Stern: En primer lugar, creo que es difícil ver el proceso que manejó el Estado sin el baile, conflictivo a veces, sinergístico otras veces, que se da con las organizaciones de la sociedad civil comprometidas con el tema de derechos humanos. Pensándolo así, yo diría que estoy en desacuerdo con una de las cosas que dijiste: creo que Argentina y Chile son los dos países que han avanzado más. En comparación con otros países, en temas como la verdad, en los actos reparatorios, y en la justicia penal, hay más procesos en esos dos países, y con más resultados. Pero, donde estoy de acuerdo, es que las dinámicas de estos procesos han sido muy distintas. En Argentina hubo un paso muy audaz al principio de la transición, con el juicio de los militares, pero ha sido un proceso más dramático en sus avances y en sus retrocesos. Porque después de estos avances, vinieron las rebeliones militares, la Ley de Punto Final, y un largo periodo en los años 90 de fuerte estancamiento. Para reinstalar los temas, se tenía que volver a articular mucha presión desde la sociedad civil, y cuando entran los Kirchner-Fernández, ahí nuevamente hay avances muy rápidamente. Si bien esto es en parte una simplificación, a lo que voy es que Argentina ha logrado hasta hoy un proceso impresionante pero con más drama de avanzar, y luego retroceder. Mientras que en Chile yo creo que el proceso empezó más tarde -el gobierno democrático no se inicia hasta 1990-, lo que quiere decir que se han podido asumir los avances, y también las derrotas que se vivieron en la Argentina durante los años 80. A veces son dos países que se ven en rivalidad, pero que siempre se están mirando y aprenden el uno del otro.

En Chile, entonces, el proceso empieza más tarde: es un proceso que podemos llamar de acumulación lenta, con una gran tentación de parar. Y eso especialmente en el Estado. Por eso los 
actores sociales son muy importantes. Porque si bien Aylwin avanza con la Comisión Rettig, y si bien antes del Boinazo actores sociales toman la doctrina Aylwin como una manera de abrir procesos judiciales, se provoca una cierta crisis. Con el Boinazo se dice "no, no vayamos por ahí". Entonces llegando a la transición de Aylwin a Frei, la clase política no tiene mucho interés. Es decir, la cautela empieza a convertirse no en un compromiso de avanzar cautelosamente, sino en la idea que ya se ha hecho todo lo que se podía hacer, y que es tiempo de detenerse. En ese momento, la presión social, desde los actores sociales es muy importante porque siempre está en tensión con esa tentación de cerrar. En este juego entre Estado y sociedad civil, se va forjando un proceso cumulativo de avances. Y ya para 2005-2006, los resultados parecen semejantes en Chile y en Argentina, solo que la dinámica del proceso es muy distinta: pero ya se ha llegado al punto en que los mismos militares están definiendo una doctrina muy distinta, y hay un acuerdo en la sociedad en que no podemos cerrar estos casos.

De esta forma, siempre se necesita un juego entre Estado y sociedad civil, y sin una sinergia, aunque sea conflictiva, es muy difícil avanzar. Me explico: sin la presión de la sociedad, el Estado va a hacer poco. Pero sin el Estado legitimando lo que está pasando, y tratando de responder de alguna manera a esa presión, tampoco se avanza mucho. Si pensamos comparativamente, eso es muy evidente. Por ejemplo, en el Perú se hizo una Comisión de Verdad excelente. Pero todo el trabajo de la Comisión, para decirlo en quechua, quedó "wakcha", es decir huérfano, porque el Estado realmente no avanzó mucho con lo que hizo la Comisión de Verdad. Esto no quiere decir que el trabajo de la Comisión era trabajo en vano, pues abrió espacio para respuestas culturales y sociales muy creativas a nivel micro, a nivel del arte, de las comunidades indígenas. Pero teniendo una Comisión de tan alta calidad y tan poco avance en el tema, resulta evidente que sin un baile sinergístico entre Estado y sociedad civil no se pueden dar ciertos pasos.

Ahora bien, lo que no se ha hecho, me parece, es ver si, más allá de la verdad, la justicia penal y las reparaciones, hemos logrado como países asumir lo que es institucionalizar el tema de derechos humanos de una manera que va a importar intergeneracionalmente, pensando en el futuro. En esto, los Museos de la Memoria, el Instituto Nacional de Derechos Humanos, la educación en derechos humanos, son cuestiones fundamentales, y ahí hay mucho trabajo que hacer. Porque existe una tensión entre memorializar para cumplir y satisfacer en algo a los que sufrieron y los que están comprometidos con el tema, y memorializar e institucionalizar para llegar a un proyecto de país en que se respeten los derechos humanos, y que logre evocar un eco en las generaciones jóvenes. Y el peligro, me parece, es que las generaciones jóvenes pueden decir "no hay nada de qué hablar, porque nosotros no estamos a favor de las dictaduras. Estamos en contra de las violaciones a los derechos humanos", y de esta forma, se acabó la discusión. En cambio, hay que pensar en cuáles son las implicancias de este tema. ¿Tiene implicancias para lo que está pasando con los mapuche? ¿Tiene implicancia para pensar qué debe ser la educación? ¿Tiene implicancia con cómo debe ser un régimen de cárceles? ¿Esto acaso no tiene que ver con los derechos humanos? Es decir, de cierta manera el gran desafío es construir desde el avance, y hacer que exista un diálogo con los temas de hoy.

\section{Marianne González: Y cuando tuviste la ocasión de estar en el Museo de la Memoria ¡te dio la impresión que la propuesta del Museo iba en ese sentido?}

Steve Stern: El Museo de la Memoria era mejor de lo que esperaba. Viéndolo de afuera pensé, "bueno, esto es una instancia del Estado, qué se puede esperar...". Pero la verdad es que fue una visita muy grata: lo trabajaron bien, partiendo primero de la universalidad de los derechos humanos, y de que hay otros países también donde se han dado regímenes de barbarie, para decirlo así -aunque no se explica mucho-. Y a partir de estas doctrinas y esas experiencias, se ubica lo que 
fue una experiencia de dictadura en Chile, y lo que fueron las violaciones de derechos humanos, $y$ una lucha de solidaridad para afirmar y plantear los derechos humanos. Así que tanto a ese nivel, como por el aspecto estético, me pareció bien. Ahora, voy a tener una crítica también. Mi impresión fue que no se logra caracterizar lo que era la sociedad chilena antes de 1973, y analizar de dónde venían estos conflictos: no pudieron instalar eso como parte de la exhibición permanente.

Sin embargo, hay un tercer aspecto que considerar: el Museo es una institución del Estado, depende su presupuesto del Estado, hay una jerarquía, etc., pero por otro lado, la legitimidad del Museo está en su capacidad de dialogar con las personas y los sectores que encuentran que el tema de memoria es importante. Entonces el Estado está en control, pero no está en control total, porque el Estado necesita que ese Museo se instale en la sociedad con cierta legitimidad. Y por eso creo que los eventos que se realizan ahí, las exhibiciones temporales, los seminarios, las conferencias, etc., van a ir definiendo hasta qué punto el Museo puede compensar por los silencios y lo que no está en las exhibiciones permanentes, pero está aún por definirse.

\section{Marianne González: Hoy en día en Chile existe una asociación casi automática entre las ideas de memoria, derechos humanos y la dictadura de 1973. Pero $i$ hay otras asociaciones en que memoria y derechos humanos se puedan relacionar no remitiéndonos a un hecho histórico puntual, en el caso de Chile a la dictadura? La asociación entre estos dos campos o conceptos ¿se arma siempre en conexión con un hecho fundador?}

Steve Stern: Es una pregunta interesante. Yo creo que no hay duda de que en Chile, en Argentina, en Uruguay, en Brasil ahora, en muchas partes, es muy difícil desligar la toma de conciencia sobre la importancia de la memoria con la toma de conciencia sobre derechos humanos y dictadura. Pero pensando de manera multicultural o intercultural, se puede decir que, aunque no tenga la energía de la consigna "memoria y derechos humanos" que era parte de una lucha para superar dictadura y provocar transición democrática, hay muchas culturas que valorizan la memoria. Y se valoriza la memoria en asociación con persecuciones de algún tipo. Pensemos por ejemplo en la memoria indígena. Es muy difícil pensar una temporalidad de solo 20, 30 o 40 años, porque el tema indígena es imposible no asociarlo con la conquista española. Entonces hay una temporalidad de 500 años, a la vez que puede existir una temporalidad más reciente. Hay un juego de temporalidades, y el valor que se atribuye a la memoria puede ser un valor muy importante, muy anterior a la dictadura, y a las guerras del siglo XX. Por ejemplo, la memoria de los Incas tiene un valor muy importante, incluidas las insurgencias del siglo XVIII en Perú. Los judíos son famosos por la asociación con la memoria también. Hay así varias culturas que piensan que la memoria tiene un valor identitario, y tiene un valor para definir cuál es nuestra lucha, o cuáles son nuestros valores.

Para pensar comparativamente, en América Latina hay también otros casos en los que se conecta un problema de dictadura y guerra sucia, por un lado, y de temporalidades distintas, por otro lado, por ejemplo Perú y Guatemala. Ahí, lo que eran las atrocidades de un régimen contra la sociedad se cruzó muy fuertemente con violencia genocida contra personas y culturas indígenas, que manejan temporalidades de más largo alcance. La misma Comisión de la Verdad en el Perú descubre que hay un $20 \%$ de la población del Perú cuyas lenguas maternas eran el quechua, u otras lenguas distintas del español. Y descubre al mismo tiempo que más o menos $75 \%$ de las víctimas del conflicto armado son personas cuyo idioma materno no era el español. Ahí, el desafío de cómo explicar esa experiencia de corto plazo sin dialogar con un problema de racismo estructural, de largo plazo, es inevitable. Tenían que enfrentar entonces este juego de temporalidades distintas.

Hay otra perspectiva desde la cual el tema de la memoria se puede desviar de lo que habíamos definido como una ligazón con la dictadura. Pensemos en el Chile de hoy con el movimiento 
estudiantil, que está en diálogo con lo que está pasando en muchas partes del mundo -el problema del endeudamiento, de que las personas sienten que hay un $1 \%$ de las personas que se aprovechan y hay un $99 \%$ que quedan atrás-. En todo ese juego, que en Chile tiene la particularidad de estar muy enfocado en la educación, podemos decir que también de alguna forma está presente el fantasma de la dictadura. Ahí hay un tema de memoria, pero planteado mucho más fuertemente desde una nueva generación, que dice que, si bien en la transición democrática hemos canalizado mucha energía en el tema de derechos humanos que tiene que ver con la vida y muerte, la desaparición y la tortura, lo que no hemos logrado hacer todavía es enfrentar otro tipo de derechos humanos: el derecho de una cierta dignidad socioeconómica, lo que significa por ejemplo acceso y oportunidades a una educación de calidad a un precio que no va a sofocar a las familias.

Marianne González: En efecto, en 2011 el gran movimiento en Chile ha sido el de los jóvenes, el de los estudiantes, y en este contexto de movilizaciones han salido a la luz muchos símbolos ligados a la dictadura como los cacerolazos $^{3}$, las manifestaciones de repudio al homenaje a Krasnoff ${ }^{4}$, o también los incidentes que se produjeron en la Universidad Católica en un homenaje que se hizo a Jaime Guzmán ${ }^{5}$, donde los mismos estudiantes se opusieron a estos homenajes. Así, estos movimientos parecen ir retomando estas luchas por la memoria del periodo de la dictadura, para darles un sentido hoy en día. ¿Pudieras ahondar un poco más en esto?

Steve: Se trata de una resignificación. Los jóvenes entienden que esos símbolos importan, quizás no entiendan toda la historia de los símbolos, pero saben que los símbolos existen, que tienen historia, y que una parte de esa historia es la protesta contra la dictadura. Creo que es todo un proceso de resignificación de lo que es la memoria. También hay una memoria sutil que pasa cuando llegamos a un sistema político altamente disfuncional. Para los que vivieron la dictadura como la respuesta a una situación de falta de gobernabilidad, el momento actual puede provocar un poco de miedo. Si bien no es el miedo de que se vaya a instalar una dictadura exactamente como antes, lo único que parece quedar es una pugna directa. Y los gobiernos empiezan a sentir el deseo de la amenaza, la mano dura como una manera de "restablecer el orden". Entonces yo creo que hay varias memorias y resignificaciones que están ocurriendo. Por un lado, las que son más evidentes en la calle usando símbolos, y por otro lado, las que pueden tener una reacción de miedo, frente al hecho que este país no logra articular las necesidades sociales con dinámicas políticas de una manera que funcione.

Marianne González: Pero también eso tiene mucho que ver con este miedo al conflicto, la idea que todo conflicto debe llevar a una confrontación, que no puede haber un conflicto sano...

Esta forma de manifestación -que consiste en golpear cacerolas- se asocia primero con las manifestaciones en los años 71-73 contra el gobierno de la Unidad Popular; y luego en los años 80, como parte de las protestas en contra de la dictadura: era una forma de manifestarse que podía realizarse sin que existiera una concentración de personas, y evitar de esta forma la represión. Durante las jornadas de mayor movilización del movimiento estudiantil de 2011, se volvieron a producir "cacerolazos" en todo el país.

4 Miguel Krassnoff es un militar que perteneció a la DINA (Dirección de Inteligencia Nacional) y que ha sido acusado y condenado a más de 100 años de cárcel por violaciones a los derechos humanos durante la dictadura. En noviembre de 2011, el Alcalde de la Comuna de Providencia, Cristián Labbé -muy cuestionado por su rol en el conflicto estudiantil-, autorizó la realización de un homenaje a Krassnoff en un recinto municipal. Esta situación generó gran revuelo político, y el día de la ceremonia se produjeron violentos incidentes a la salida del homenaje.

5 Jaime Guzmán fue el principal ideólogo de la dictadura militar en Chile. Con el retorno de la democracia, fue elegido senador por el partido de la Unión Democrática Independiente (UDI), y en 1991 fue asesinado. En 2011 se realizaron homenajes por los 20 años de su muerte, en los cuales los estudiantes también se manifestaron en contra de la figura de Jaime Guzmán. 
Steve Stern: Exacto, es como si la democracia no tuviera como supuesto qué es conflicto y cómo resolver conflictos. Si no hay conflictos no hay democracia, pero si no hay capacidad de resolver en algo estos conflictos, tampoco.

Marianne González: En ese sentido, se dice mucho que esta generación que se atrevió a salir a la calle parece haberse liberado de la memoria del miedo, de esta memoria de la represión. ¿Es así?

Steve Stern: Creo que sí. Si pensamos históricamente lo que era la transición democrática, muchas personas a principios de los años 90, incluyendo a personas que no estaban de acuerdo con la política del gobierno de Aylwin, sentían la necesidad de cuidar la transición, entendían que era frágil, y que Pinochet era comandante en jefe del Ejército. Esa tensión era una situación muy difundida y no era una manipulación desde arriba, sino que era algo que se instaló como una cautela. Entonces es solo una nueva generación la que logra decir "nosotros vamos a salir a la calle". Hay una dinámica generacional que logró deshacerse del miedo.

Marcela Sandoval: Pero también se ha hablado, en el contexto de la instalación de un gobierno de derecha, del fin de la transición, junto con un fuerte retroceso en términos simbólicos. Ejemplos hay varios: el homenaje que un alcalde le hace a un militar implicado en violaciones a los derechos humanos; el reemplazo de la palabra "dictadura" por "régimen militar" en el currículo escolar, decisión que además se toma en medio del movimiento estudiantil...

Steve Stern: Hay un Chile posterremoto en todos los sentidos. El terremoto geológico, pero también el terremoto político en su sentido cultural, que ocurrió en la calle. En este Chile, con un gobierno de centro derecha, es posible preguntarse hacia dónde va el simbolismo y el tema de la memoria. Yo soy optimista, pero la relación del Estado con los actores sociales no va a ser un baile favorable para la memoria y los derechos humanos, más bien se dará una pugna para restablecer un baile que funciona desde la perspectiva de los derechos humanos.

Así, se puede decir que terminó la transición democrática, pero no ha terminado la lucha en torno a la memoria. Esta lucha no ha terminado, no para las generaciones más viejas para quienes lo importante era superar el fantasma de volver hacia la dictadura, sino para las más jóvenes que están redefiniendo en qué consiste el tema. Pero están redefiniendo en un momento que políticamente es un poco disfuncional, en que no hay un baile eficaz entre la sociedad civil y el Estado. Por ejemplo, se discute todavía la cuestión del sistema electoral binominal, que es un tema muy ligado a la memoria de una Constitución heredada de la dictadura. El problema entonces es si se puede volver a organizar un sistema político un poco más funcional, para que la gente no suponga que su único recurso es estar en la calle.

Marianne González: Por otro lado, la derecha hoy en día ya no puede hablar sin los derechos humanos, ni en contra de los derechos humanos, por lo menos de forma directa. En ese sentido, sí ha habido un avance.

Steve Stern: Ese es un avance en la cultura pública. Se puede hacer una analogía con los movimientos de derechos civiles que tienen que ver con el tema racial en Estados Unidos: estos movimientos no disolvieron el racismo ni la jerarquía racial en Estados Unidos, pero sí permitieron, entre otras cosas, que es imposible ser explícitamente racista hoy en día. Hay un avance, pero es un avance agridulce. En Chile, nadie puede estar hoy explícitamente en contra de los derechos humanos, pero no significa que el problema está resuelto. Significa que el proceso de luchar a favor de estos derechos es un proceso más sutil, y significa también que hay una posibilidad de autocomplacencia por parte de quienes quisieran creer que el problema se resolvió. 
Marcela Sandoval: ¿La pedagogía de la memoria puede cumplir una función en ello? Si uno revisa el currículo escolar y los programas de algunas carreras, es muy incipiente la incorporación de contenidos que tengan que ver con derechos humanos. ¿Qué ha dicho la experiencia comparada?

Steve Stern: Voy a responder esta pregunta con otra pregunta. ¿Qué es lo que aprenden los niños en los colegios? ¿Están aprendiendo los textos organizados por el Ministerio de Educación o están aprendiendo cómo son las relaciones sociales, cómo son las jerarquías? Es decir, me parece que una pedagogía de derechos humanos también debiera consistir en lo que está pasando en la práctica en los colegios y las universidades. Porque si pensamos que las personas aprenden del texto mandatorio, la lucha y la energía están en revisar todo eso. Pero si pensamos que esa es solo una parte del juego, pero no la parte más importante, entonces el desafío es distinto. Por eso es relevante preguntarse dónde está el foco. Yo no sé cuál es la respuesta, pero dudo que los textos formales escolares sean suficientes como una respuesta a estos problemas. No es que el contenido no importe. Pero como intelectuales tenemos nuestro talón de Aquiles al suponer que si el texto está bien, todo va a estar bien. Yo no tengo ninguna fórmula, pero a mí me parece interesante saber de qué manera se puede impulsar una educación en derechos humanos que lleva realmente a la persona a una reflexión apropiada en términos de la dificultad para su edad. En ese sentido me parecen muy importantes los lugares que son sitios de memoria, no como una visita tradicional, sino algo más interactivo. Sé que en Villa Grimaldi están tratando de pensar en formas mucho más creativas, con mucha autocrítica también, por ejemplo, en una visita al Sitio, luego una clase, después llevando grupos para trabajar con el archivo oral: un proceso que pueda abrir a la reflexión.

Marianne González: Además de lo que pasa en las aulas, también tiene que haber otros aspectos de la cultura que puedan ir ayudando en ese sentido. Por ejemplo, algo que ha llamado bastante la atención estos años, han sido las series de televisión como Los Archivos del Cardenal o Los ${80^{\prime}}^{6}$, que crearon también otra manera de llegar a los hogares, a los jóvenes, una manera de hacer memoria y de crear conciencia, que va acompañando los procesos más institucionalizados.

Steve Stern: Sí, yo creo que eso es muy importante y puede ser muy útil como herramienta de enseñanza. Por ejemplo, podría partirse de un episodio de estas series, y analizar de qué manera, cediendo a lo que tiene que ceder un programa de televisión, lo que se relata es real o no, y qué está en juego aquí. Esto podría ser un proyecto de investigación-enseñanza. Otra manera en que podamos aprender sobre estas cosas, es pensando en el Perú. Cuando el Estado peruano, después de la Comisión de la Verdad, deja huérfanas a las comunidades, se puede ver que desde la cultura se logran inventar cosas para trabajar la memoria del conflicto armado. En Perú llaman la atención, por ejemplo, los concursos de arte que se hicieron después de la Comisión de la Verdad en que fueron las comunidades y las personas las que empezaron, no a escribir historia, sino a tratar de entender lo qué pasó y plasmarlo en forma de arte. Hay algunos experimentos ahí, que provocan el pensamiento de qué se puede hacer a nivel micro.

Marcela Sandoval: De lo que se ha hecho en Chile en términos de la investigación en memoria, tenemos la impresión de que se ha concentrado en esfuerzos específicos desde la historia, la sicología social, la literatura, pero que ha sido poco interdisciplinario, y sería interesante apuntar

\footnotetext{
Los Archivos del Cardenal es una serie de televisión estrenada en 2011 que retoma el trabajo de la Vicaría de la Solidaridad en su lucha contra la dictadura en el periodo 1973-1978. Los '80 fue estrenada en 2008 y sigue siendo transmitida hasta el día de hoy, y relata la historia de una familia de clase media durante los años 80, con el telón de fondo de la dictadura militar.
} 


\section{a esfuerzos interdisciplinarios porque pudieran ser estratégicos en términos de cómo la academia se plantea estos temas.}

Steve Stern: Es un tema importante. Voy a compartir mi experiencia con la Trilogía. Yo no sabía que iba a escribir una trilogía, yo pensaba que iba a escribir un libro de historia. Pero las experiencias que se vivieron en Chile -también en Argentina, en Perú, en Guatemala, en El Salvador- son experiencias límite, lo que un jurista llamaría crimen contra la humanidad, pero lo que un filósofo llamaría mal radical. Esas experiencias más allá de los límites "normales", pero que son tan frecuentes que a veces comienzan a ser normales, crean un peso enorme de cómo representar, cómo narrar tales experiencias.

Como historiador, no sólo por el desafío intelectual, sino por la magnitud de lo humano, yo empecé a preguntarme cómo iba a cumplir con lo que significa ese peso humano. Y pensé que no lo podía hacer escribiendo un libro con el estilo clásico de un libro de historia. Primero tenía que empezar a partir de personas humanas, y con ello construir una teoría de la memoria-historia. Y solo después podía narrarse una historia de "lo que pasó" analizando el papel de la memoria en desarrollar lo que fue la lucha social, política, cultural, etc.

Así, descubrí en el camino que necesitaba una cierta apertura interdisciplinaria, justamente porque las convenciones de las disciplinas de cierta manera reproducen el problema, porque no se enfrentan en el fondo a lo humano. Decidí entonces que tenía que escribir un libro en otra voz. Este libro es el tomo I de la Trilogía. Un libro que no es exactamente historia, sino entre etnografía, literatura e historia. Entonces pude ver, desde mi propia experiencia, lo rico que es pensar estos problemas desde la interdisciplinariedad y también lo desafiante que es. Creo que para quienes trabajan estos temas, es muy importante tener formación interdisciplinaria, tanto a nivel humano, a nivel cívico, y a nivel intelectual.

\section{Marcela Sandoval: En derechos humanos existe un imperativo ético para la gente que trabaja desde la academia en estos temas, de tener una cierta posición y no ser "neutral". ¿Qué piensas tú?}

Steve Stern: Yo creo que hay una diferencia entre ser neutral y ser no objetivo. Objetivo en el sentido de autocuestionarte y desafiarte sobre lo que es la sociedad en tu mirada, en vez de sencillamente armar una consigna o simplemente ser autocomplaciente con tus propios valores.

Por ejemplo, en el tomo I de la Trilogía yo empiezo el primer capítulo con el relato de una entrevista a una persona que Ilamo "Doña Elena" que es pro Pinochet, que proviene de una familia de la aristocracia venida a menos de antiguos terratenientes. Es una decisión muy consciente el empezar desde ahí, porque es una manera de decir que la historia de la memoria tiene que ser la historia de toda la sociedad, tiene que de alguna manera reconocer a todos en el espejo. De otra manera, no voy a entender la memoria. Puede ser que haga otra cosa que valga la pena, pero no voy a entender por qué, al Ilegar al Plebiscito de 1988, Pinochet todavía tenía 43\% de aprobación, aun después de todo lo que pasó económicamente y en materia de derechos humanos. Tenía que entender eso, que era obviamente muy impactante. Entonces había que comenzar desde ahí, con el relato de "Doña Elena".

Ahora, eso me creó un problema: cómo hacer esto y ser fidedigno con ese tipo de personas, pero al mismo tiempo, no hacer una historia apologética de esas personas. Para esto, en el relato tomo pausas como ser humano, y digo "vamos a reconocer que puede hervir la sangre al escuchar lo que pueden decir estas personas". Eso no es historia estándar. Ahí hay una postura, pero trato de utilizar la postura para decir que hay que entender eso, y no solo quedarme con reconocer mi propia indignación. Yo creo que es muy importante, porque de otra manera no vamos a entender la sociedad. Así que yo discrepo con la idea de que tener postura es no poder ser crítico frente 
a los supuestos que tiene tu propio lado, y no poder intuir una visión que toma en serio los que están en el otro lado, y que va más allá de sencillamente denunciarlos.

\section{Marianne González: ¿Pero se puede hacer derechos humanos sin postura?}

Steve Stern: No, yo creo que todos tenemos postura, somos personas cívicas, y la postura de no tener postura es un escape superficial. Es más, yo creo que los regímenes de guerra sucia y de dictadura funcionaron en parte por tratar de entrenar a la población en no tener postura. Entonces el no tener postura es reproducir una visión de la sociedad tecnificada de los de arriba, y una sociedad que no presta atención a lo que están haciendo los que mandan. Yo honestamente creo que la postura de no tener postura no es factible en general, y en particular en el caso de los derechos humanos. 
